MIDAS

Museus e estudos interdisciplinares

$1 \mid 2013$

Varia

\title{
Teorias da conservação e desafios relacionados aos acervos científicos
}

Conservation theories and challenges related to scientific collections

\section{Marcus Granato e Guadalupe do Nascimento Campos}

\section{(2) OpenEdition}

Journals

\section{Edição electrónica}

URL: http://journals.openedition.org/midas/131

DOI: $10.4000 /$ midas. 131

ISSN: 2182-9543

\section{Editora:}

Alice Semedo, Paulo Simões Rodrigues, Pedro Casaleiro, Raquel Henriques da Silva, Ana Carvalho

\section{Refêrencia eletrónica}

Marcus Granato e Guadalupe do Nascimento Campos, "Teorias da conservação e desafios relacionados aos acervos científicos », MIDAS [Online], 1 | 2013, posto online no dia 29 abril 2013, consultado no dia 21 dezembro 2020. URL : http://journals.openedition.org/midas/131 ; DOI : https:// doi.org/10.4000/midas.131

Este documento foi criado de forma automática no dia 21 dezembro 2020.

\section{c) (i) (2)}

Midas is licensed under a Creative Commons Attribution-NonCommercial-ShareAlike 3.0 International License 


\section{Teorias da conservação e desafios relacionados aos acervos científicos}

Conservation theories and challenges related to scientific collections

Marcus Granato e Guadalupe do Nascimento Campos

\section{1 - Introdução}

1 As coleções patrimoniais são a base sobre a qual os museus constroem e reforçam o seu papel social e a identidade cultural. Permitem redescobrir os povos, as migrações, os movimentos e as idéias que criaram e deram forma às sociedades e às civilizações. 0 desafio consiste em preservar essas coleções patrimoniais, de modo a transmitir aspectos relacionados ao passado, enriquecer o presente e construir o futuro.

É importante esclarecer que, como apresentado por Beatriz M. Kuhl (2006, sp), “na concepção contemporânea alargada sobre os bens culturais, a tutela não mais se restringe apenas às 'grandes obras de arte', como ocorria no passado, mas se volta também às obras 'modestas' que com o tempo assumiram significação cultural”.

3 Complementando esse esclarecimento, o que consideramos como patrimônio cultural material, objeto de interesse da conservação, são aqueles objetos/monumentos que se destacam dos demais por um processo de significação, que se formaliza quando da escolha para que façam parte desse conjunto. 0 que os diferencia dos demais, na moderna concepção pelo viés da Museologia, inclui a noção de comunicação, que pode traduzir-se de formas diferentes: significância, simbolismo, conotação cultural, metáfora, etc. Os objetos de interesse da conservação têm em comum sua natureza simbólica, são símbolos e todos têm o potencial de comunicação, seja de significados sociais, seja de sentimentais.

o patrimônio cultural da Ciência e Tecnologia (C\&T) inclui o conhecimento científico e tecnológico produzido pelo homem, além de todos aqueles objetos (também englobando documentos em suporte papel), coleções arqueológicas, etnográficas e espécimes das coleções biológicas que são testemunhos dos processos científicos e do desenvolvimento tecnológico. Também se inserem nesse grande conjunto as construções arquitetônicas 
produzidas com a funcionalidade de atender às necessidades desses processos e desenvolvimentos.

5 Nos primeiros itens do presente trabalho serão apresentadas as principais ideias que nortearam e ainda orientam as intervenções de conservação. A seguir, serão abordadas as formas de conservação relacionadas aos acervos científicos. Constituindo parte do patrimônio cultural, esses acervos, em geral, são raramente objeto de iniciativas de preservação.

Nesse texto, também serão abordados os acervos dos chamados "instrumentos científicos" e como as teorias da conservação se aplicam e se relacionam ao caso em questão. Finalmente, a partir das discussões relacionando as teorias de conservação para o caso específico dos objetos científicos, são discutidos alguns desafios relacionados à preservação desse tipo de acervo.

\section{2 - As Primeiras Teorias da Conservação}

7 A conservação com base científica inicia-se no séc. XIX. Destacam-se os trabalhos de Sir Humphrey Davy, presidente da Royal Society (1820), estudando os papiros de Pompéia; de C. J. Thomson, no Museu Nacional de Copenhague, desenvolvendo técnicas para conservar objetos arqueológicos, e com Friedrich Rathgen (Gilberg 1987), em 1888, no Museu Real de Berlim, onde criou um laboratório e desenvolveu uma série de tratamentos de conservação. Produziu, em 1898, um dos primeiros livros sobre o tema (Die Konservierung von Altumsfunden - A Conservação de Antiguidades). Ainda nesse século, temos o advento da ciência como caminho para a revelação da verdade e para análise da realidade, além da ampliação do acesso público à cultura. 0 nacionalismo exalta o valor dos monumentos nacionais como símbolos de identidade, o romantismo consagra o artista como indivíduo especial e exalta a beleza das ruínas e as artes e os artistas têm um reconhecimento especial.

8 É nesse contexto, também moldado pela Revolução Industrial, na Inglaterra, e pelas guerras Napoleônicas, na França, que despontam os primeiros teóricos da conservação, John Ruskin (1819-1900) e Eugène Emmanuel Viollet-le-Duc (1814-1879). Suas posições, diametralmente opostas, relacionam-se diretamente com esse contexto e, com o tempo, outras teorias foram sendo elaboradas.

9 Ruskin foi um escritor inglês com grande influência sobre os artistas e os amantes das artes. Com idéias de cunho socialista, empenhava-se em causas sociais. É considerado um dos primeiros teóricos da restauração; publica em 1849, o livro The Seven Lamps of Architecture, obra que trouxe grande repercussão das suas ideias, e, dois anos depois, o primeiro volume de The Stones of Venice ${ }^{2}$, onde advogou pelo ruinismo em detrimento da restauração. Neles, ele defende veementemente os valores dos prédios antigos. Seu amor pelo passado era tão apaixonado que produzia um certo desprezo pelo presente. Venerava a pátina e a denominava de mancha dourada do tempo (Ruskin 2008, 28).

Avesso a qualquer intervenção de restauro e da imitação da linguagem de estilos passados, alegava que o aspecto principal da preservação de um edifício é o histórico e não a sua beleza. Os materiais originais deveriam ser preservados e respeitados sem alterações e a restauração era "considerada a mais completa destruição que um edifício poderia sofrer" (Choay 1996, 155). 
11 Seu seguidor William Morris (1834-1896) partilhava de suas convicções sobre a importância dos materiais originais constituintes do monumento e achava que entre os agentes perturbadores estavam aqueles que tentavam reconstruir prédios danificados. Enquanto na Inglaterra, a Revolução Industrial trazia influências diversas para a sociedade inglesa, na França, um dos resultados das guerras napoleônicas foi o dano a diversas construções góticas e seu restauro foi considerado uma tarefa nacional. Nesse ambiente, Eugène Emmanuel Viollet-le-Duc, arquiteto responsável por muitas dessas obras (Notre Dame de Paris, Saint Chapelle, La Madeleine de Vézelay, etc.), considerava-se autorizado a preencher as lacunas deixadas pelos danos nas edificações. Foi o primeiro a compilar de forma sistemática os princípios de uma teoria de restauração arquitetônica (González-Varas 2008). Para ele a edificação deveria ser restaurada ao melhor estado possível, para uma condição que poderia nunca ter existido, desde que coerente com a natureza verdadeira da concepção original da construção.

Em 1866, após vários anos de prática em obras de restauração, publica o oitavo volume do seu Dictionnaire Raisonné de l'Architecture Française du XIème au XVIème Siècle, onde apresenta sua definição para restauração - "Restaurar um edifício não significa repará-lo, reconstruí-lo ou mantê-lo. Significa restabelecê-lo no seu estado mais completo, que pode até nunca ter existido" (Viollet-le-Duc 2000,17).

14 Em seus trabalhos de restauro, Viollet-le-Duc realizava diversas intervenções, muitas vezes "corrigindo" o projeto que parecia a ele defeituoso. Acreditava que através do conhecimento profundo de um sistema, poderia criar uma forma ideal para impô-la no monumento a ser restaurado. Por outro lado, defendia a pesquisa detalhada sobre o objeto do restauro e a ampla documentação sobre as intervenções realizadas, princípios válidos até os dias atuais.

15 Entre as duas posições extremadas de Ruskin e de Violet-le-Duc, vários teóricos apresentaram idéias intermediárias. Destacamos o arquiteto italiano Camillo Boito (1836-1914) que estabeleceu alguns princípios que ainda hoje são bem aceitos, por exemplo: a necessidade clara de diferenciações entre as partes originais e as restauradas; a mínima intervenção ou reversibilidade, dentre outros. Boito (2002) elaborou uma teoria intermediária, favorável à conservação dos acréscimos incorporados à obra arquitetônica.

16 Em 1884, realiza-se o Congresso de Engenheiros e Arquitetos, em Roma, e Boito propõe os oito princípios básicos do Restauro Arqueológico, onde se aceita apenas a consolidação e recomposição das partes desmembradas e a conservação para não ser preciso restaurar, afirmando alguns dos princípios de Ruskin e Morris.

17 No início do século XX, o historiador da arte austríaco Alois Riegl considerava que o objeto existe enquanto um elemento a ser preservado quando lhe é atribuído um valor histórico, artístico e cultural (Cunha 2006). De acordo com Maria J. M. Justicia e colaboradores, a análise de Riegl se estrutura

através de categorias de valores, os que chama de rememorativos, ligados ao passado, que necessariamente fazem parte da memória (valor de antiguidade, valor histórico e valor rememorativo intencionado). Junto a eles os chamados "de contemporaneidade", que pertencem ao presente (valor instrumental e valor artístico: a) de novidade, b) artístico relativo (Justicia 2008, 14).

18 Para ele os critérios de preservação dos monumentos eram aplicados para qualquer obra humana com certa antiguidade e simbolismo sentimental ou social e não apenas pela singularidade e excepcionalidade histórica ou artística (Riegl 2006). 
19 Em 1912, o pensamento evolui com a Teoria do Restauro Científico, de Gustavo Giovannoni, Luca Beltrami e Camillo Boito, dentre outros, como sendo a operação de tão somente consolidar, recompor e valorizar os traços restantes de um monumento. A teoria defende antepor a conservação em relação à restauração, não a excluindo, mas aceitandoa com limitações e como forma de consolidação (Macarrón 2008).

20 A restauração científica sustentava-se em evidências documentais, evitava tanto o fatalismo passivo de Ruskin como o intervencionismo de Viollet-le-Duc. Caracterizava-se por métodos e conhecimentos próprios das ciências humanas, sendo também denominada de arqueológica, histórica ou filológica (Muñoz Viñas 2005).

21 Nesse período, as várias teorias sobre a conservação de patrimônio provocavam muitas discussões, gerando muitas divergências e críticas. Para tentar minimizar essas discussões, muitos profissionais e instituições se debruçaram na tentativa de normalização de procedimentos básicos, que geraram as chamadas "Cartas Patrimoniais", documentos normativos que resultam do acordo entre especialistas e conservadores profissionais.

No rastro da Segunda Grande Guerra Mundial, muitos monumentos e coleções inteiras ficaram danificados, gerando um movimento de questionamento dos conceitos do "Restauro Científico" que exigiam postura de quase neutralidade do arquiteto/ conservador em relação ao bem cultural. Uma nova postura prevaleceu, o Restauro Crítico, com uma atitude mais flexível por parte dos profissionais, principalmente europeus, face à pressão social e política pela recomposição de monumentos e objetos danificados.

Em 1964, durante um congresso em Veneza, os princípios do Restauro Científico voltam a prevalecer, sendo ampliados e revistos na Carta Italiana de Restauro de 1972, por Cesare Brandi.

Nascido em Siena, Brandi foi professor universitário, crítico de arte e musicólogo, e o primeiro diretor do Istituto Centrale di Restauro, a primeira instituição desse tipo, fundada em Roma em 1939 (Price et al. 1996). Brandi produziu o primeiro sistema de pensamento completo e orgânico na área de restauração. A sua teoria do restauro é inspirada pela filosofia de Benedetto Croce; do historicismo derivou um conceito fundamental que continua plenamente válido: o caráter transiente, parcial e relativo de qualquer restauração, mesmo a mais habilidosa, por ser sempre marcada pelo clima cultural no qual é realizada.

Brandi dividia os objetos, em relação à restauração, em dois grupos: os produtos industriais e as obras de arte. Em relação ao primeiro grupo, o propósito fundamental da restauração seria restabelecer as propriedades funcionais do produto (Brandi 2000). Nesse aspecto a teoria de Brandi é limitada e cabe ressaltar que também devem ser considerados aspectos estéticos e históricos na conservação desse tipo de objetos que compõem em grande parte o patrimônio científico e técnico.

Brandi definia restauração como o momento metodológico no qual a obra de arte é apreciada em sua forma material e dualidade histórica e estética, com uma visão de transmiti-la para o futuro. Essa visão humanista, que sublinha sua concepção de restauração, é um aspecto muito valioso da teoria de Brandi. Para ele a restauração não é uma técnica auxiliar, mas um momento de apreciação crítica do objeto; em outras palavras, é um aspecto da pesquisa estética e filológica em direção à sua compreensão. 
27 A restauração recriaria a unidade do objeto perdida pelos efeitos do tempo ou de restaurações anteriores. Para alcançar esses objetivos a restauração deveria concordar com princípios históricos (não destruir os traços da passagem do tempo e da intervenção humana) assim como os estéticos (remover acabamentos errados e alterações inapropriadas). Na prática, as exigências estéticas freqüentemente prevaleciam sobre as históricas no pensamento de Brandi (Price et al. 1996). Publicou em 1963 a Teoria do Restauro, texto que defende a relevância de um fator quase sempre negligenciado na conservação científica: o valor artístico do objeto.

\section{3 - Conceitos mais Recentes}

28 No decorrer do século XX, algumas teorias e concepções sobre a conservação coexistiram. A partir de meados desse século, a visão estética coexistiu com outra contribuição significativa para a conservação, a chamada "Nova Conservação Científica", que foi mais um movimento em prol do uso de técnicas e metodologias científicas na conservação do que propriamente uma teoria da conservação. Nenhum esforço teórico foi realizado para validar essa abordagem. Nessa concepção, os cientistas e a metodologia científica passam a ser determinantes para o processo da preservação de acervos e, em função dos bons resultados, essa abordagem torna-se, no final do século XX, a forma reconhecida de lidar com a preservação de acervos.

As últimas décadas do século XX também são marcadas pelas teorias de Garry Thomson, que propiciaram a publicação do livro The Museum Environment (1988). São colocados pela primeira vez, de forma sistemática, os problemas referentes à climatização em museus e a importância do controle do ambiente onde estão colocadas as coleções.

Salvador Muñoz Víñas (2005), mais recentemente, faz a sistematização e a crítica das ideias de teóricos anteriores. Essas teorias teriam como pressuposto ser a conservação uma operação de imposição da verdade, de relevância apenas para um grupo restrito de formação específica, autorizadas a dizer como se deve conservar e restaurar.

31 Muñoz Viñas propõe uma teoria contemporânea da conservação onde o interesse primário está nos sujeitos e não mais nos objetos. A objetividade na conservação, fundamento da abordagem científica prevalente a partir do final do século XX, seria substituída por uma forma de subjetivismo. Nessa "teoria contemporânea" a noção de verdade é substituída pela comunicação, que pode traduzir-se de formas diferentes: significância, simbolismo, conotação cultural, metáfora etc. Os objetos de interesse da preservação têm, portanto, em comum sua natureza simbólica, todos são símbolos e todos têm um potencial de comunicação, seja de significados sociais, seja de sentimentais. A verdade deixa de ser o critério de orientação da conservação. 0 conservador não deveria impor a verdade, mas sim facilitar a leitura do objeto para melhor compreendê-lo e para favorecer seu potencial de comunicação.

De acordo com Muñoz Viñas (2005), a conservação seria realizada com a participação de pessoas para as quais o objeto tem significado. Portanto, esses interesses (necessidades, preferências e prioridades) deveriam ser considerados como o fator mais importante no processo de decisão (Granato 2007).

33 A "teoria contemporânea" não recomenda colocar nas mãos do público geral todas as decisões relativas à conservação e ao restauro, mas apenas as pessoas afetadas pelo objeto. A teoria sugere uma democracia conduzida por representantes sociais e 
profissionais qualificados e pretende estabelecer uma relação dialética e não impositiva entre as idéias do conservador, do restaurador, do político, do cliente, do cientista e das pessoas afetadas. Esse caminho de consenso torna-se muitas vezes impraticável, em função das posições pessoais dos atores sociais envolvidos, o que pode por em cheque a prática da teoria de Viñaz. Do ponto de vista ético, Muñoz Viñas diz que "uma boa restauração é a que satisfaz um maior número de sensibilidades" $(2005,177)$.

Hoje, no início do século XXI, a conservação preventiva desponta como fator influente na pesquisa científica. Uma abordagem mais crítica do "não tocar" foi desenvolvida, baseada num melhor conhecimento dos problemas de conservação e dos mecanismos de degradação dos objetos, assim como no conhecimento do fracasso de alguns materiais modernos que foram introduzidos nessa área.

\section{4 - Os Acervos Científicos e as Teorias da Conservação}

35 A pesquisa científica orientada para as inovações oferece um potencial inesgotável, em resposta à busca pela maior precisão. Os instrumentos científicos, em contrapartida, tornam-se obsoletos cada vez mais rápido e o desaparecimento do seu conteúdo documental pode constituir a perda de uma parte intrínseca do conhecimento. A noção de conservação aparece como uma primeira etapa necessária a garantir a salvaguarda desses instrumentos de caráter histórico.

36 Esses objetos, essenciais à astronomia, à medicina, à física, à meteorologia, à matemática e demais ciências, apresentam técnica de fabricação geralmente muito complexa e os diversos materiais de que podem ser construídos exigem cuidados bem específicos e diferenciados de conservação.

37 A restauração de instrumentos científicos é uma prática recente, onde falta uma tradição bem estabelecida (Brenni 1999). Tem sido realizada mais frequentemente prestando atenção aos aspectos técnicos do que ao valor histórico dos instrumentos. A literatura mundial sobre o assunto é reduzida e os poucos tratados existentes ajudam simplesmente a reparar instrumentos.

38 Como parte dos bens culturais científicos, os instrumentos e aparatos científicos se distinguem dos artístico-arqueológicos pelo fato de que pressupõem o funcionamento. 0 funcionamento é fato constitutivo desses bens culturais e no restauro e conservação esse aspecto assume importância determinante (Miniati, Brenni 1992). No entanto, essa pode não ser a característica mais importante do objeto, pois os valores estético, técnico, econômico e artístico, além de outros fatores, podem contribuir para a sua valoração.

O restauro de instrumentos científicos apresenta correntes de pensamento diversas, como é comum para os demais objetos culturais e, claramente, surgem duas vertentes divergentes. Na primeira, procura-se como objetivo fundamental do restauro o restabelecimento da funcionalidade do instrumento. Nesse caso, o pensamento de VioletLe-Duc e a teoria de Brandi para objetos funcionais estariam em harmonia com essa premissa. Quer dizer, procura-se colocar o objeto em funcionamento, como assim era quando foi fabricado, desde que essa é a característica que o diferencia dos demais objetos culturais. Muitas vezes isso determina intervenções significativas e que podem alterar algumas características do objeto. $\mathrm{Na}$ segunda vertente, procura-se fundamentalmente preservar as evidências históricas contidas no objeto, muitas vezes determinando o não 
funcionamento da peça. Nesse caso, o pensamento de Boito e, mesmo, a teoria de Brandi relacionada aos objetos de arte se harmonizam com esses objetivos.

Alguns autores apresentam muitos argumentos a favor da primeira abordagem, dentre eles destaca-se Mann (1994), do Science Museum (Londres). Partindo da discussão sobre a ética dominante na maioria dos museus (de arte, arqueológicos, etnográficos, históricos etc.) onde a preservação das evidências históricas seria o objetivo fundamental, conclui que esta não se adequaria aos museus de ciência. Uma nova ética seria mais apropriada a esses museus e teria como objetivo primordial a exploração do artefato para benefício do público em detrimento da simples preservação de evidências materiais e históricas.

Por outro lado, ainda no Reino Unido, seguindo a tradição de Ruskin e Morris, uma visão mais conservacionista é encontrada em Newey (2000). A autora considera que a utilização de réplicas seria a forma mais adequada de passar ao público a informação desejada e não pelo funcionamento de objetos históricos.

42 A questão sobre o funcionamento ou não de objetos museológicos é uma fonte constante de debates dentro e fora da profissão museológica. A visão conservacionista tem prevalecido, apoiando-se em que a ética da profissão museológica reside no fato de que o objetivo primordial de um museu é a preservação de evidências materiais, que podem então ser exploradas de uma série de formas para benefício público.

Levando em consideração o pensamento de Muñoz Viñaz, no aspecto relacionado à decisão compartilhada sobre as intervenções em objetos culturais incluindo aqueles que valoram os objetos em questão, quais seriam os atores que atribuiriam valor a esse tipo de acervo? A sociedade reconhece o valor desses bens? Os cientistas valoram os objetos antigos de seus laboratórios, que já não produzem as medidas mais acuradas, mais exatas? Os historiadores, em especial os da ciência, valoram esse tipo de patrimônio e trabalham para seu reconhecimento e preservação?

Talvez sejam os profissionais da preservação desses acervos e que trabalham nas poucas instituições que guardam o patrimônio científico que normalmente reconheçam o valor desses artefatos. Cabe a nós partir para a conscientização de outros desses atores ${ }^{3}$.

Definitivamente, secionar um artefato ou desgastá-lo através de seu funcionamento, pode comprometer as evidências históricas e não deve ser permitido. 0 mais interessante seria proceder de forma intermediária, quando o objeto fosse de fabricação em série, quer dizer que alguns exemplares estariam disponíveis, ou despidos de importância histórica em si, seria justificável realizar uma intervenção mais profunda, buscando seu funcionamento. Por outro lado, naquelas peças muito especiais, com alto conteúdo histórico ou quando a peça for única, seria mais adequado tratar a peça no sentido de conservá-la preventivamente, utilizando réplicas para permitir a melhor compreensão do objeto pelo público.

\section{5 - Desafios para a Conservação de Acervos Científicos}

Coleções e conjuntos de instrumentos científicos apresentam desafios diversos que, muitas vezes, se relacionam com seu período de fabricação. Artefatos fabricados até o início do século XX são confeccionados em materiais mais nobres e com menos variedade do que os instrumentos mais recentes, fabricados a partir de meados do século XX. Outro aspecto que também tem relação com o período de fabricação diz respeito à complexidade 
do funcionamento do instrumento. À medida que adentra-se ao século XX, o funcionamento desses artefatos torna-se cada vez mais complexo e menos passível de entendimento pelos profissionais dos museus.

Maia e Granato $(2009,8)$ identificam ainda outros desafios que conservadores desse tipo de patrimônio enfrentam: a falta de conhecimento específico sobre esses objetos e de uma compreensão definida do trabalho de conservação nos mesmos.

A seguir serão abordados três aspectos diferentes que trazem problemas e soluções diversas para a conservação desses artefatos: os materiais constituintes, o funcionamento do objeto e a questão da coleta de peças do patrimônio científico na atualidade.

Quanto aos materiais de fabricação, instrumentos e aparatos fabricados nos séculos XVIII e XIX são feitos essencialmente de metal (latão e bronze, e prata em menor grau), estando sujeitos à corrosão e a outros problemas associados a objetos metálicos. Além desses metais, muitos instrumentos incorporam o vidro, a madeira, o marfim e couros diversos. Quanto mais antigo o objeto, em geral, mais materiais nobres estão em sua constituição, chegando a incluir materiais preciosos como o ouro e também a madrepérola (Simpson, Huntley 1996).

o bronzeamento, o acabamento acetinado e o envernizamento constituem-se em características próprias a muitos instrumentos científicos (Brenni 1986). Esses tratamentos foram aplicados aos metais para uma melhor resistência à corrosão, para diminuir a reflexão do sol e também por motivos decorativos. Esses acabamentos são parte integrante dos instrumentos, mas apresentam-se muitas vezes danificados por limpezas ou restaurações pouco escrupulosas. Ao se optar pela restauração, qual o verniz ou tinta a ser utilizado nas partes desprotegidas, aqueles que sejam atuais ou utilizando as receitas encontradas nos livros da época, refazendo assim um similar ao que era originalmente empregado? Até o final do século XX optava-se, em geral, pela segunda alternativa, já que o tom dourado final das peças tinha relação com esse tipo de acabamento. A partir do século XXI, verifica-se em muitos casos a tendência a utilizar vernizes e tintas atuais e com alto poder de proteção contra a corrosão e que não resultarão, no futuro, na compreensão errônea de que, por terem composição similar ao original, seriam originais (Granato e Tully 2009).

51 Cada material constituinte do instrumento científico exige um tratamento específico e a diversidade de materiais que se incorporam ao objeto, e interagem com o mesmo ambiente, resulta em maior complexidade para o gerenciamento dos problemas de preservação relacionados. Assim, à medida que os museus incorporam objetos mais recentes, especialmente das últimas décadas do século $\mathrm{XX}$, novos desafios surgem, incluindo ligas metálicas em ampla variedade de composições, plásticos e materiais cerâmicos, e apresentam novos e grandes desafios para a conservação (Shashoua 2008; Grattan 1993).

52 São desconhecidos os comportamentos desses materiais nos ambientes museológicos e quais seriam as condições mais adequadas para sua preservação e a própria identificação desses materiais fica cada vez mais complexa, exigindo a utilização de técnicas e instrumental de análise nos quais os laboratórios de conservação muitas vezes não estão capacitados ou que são muito caros para os recursos disponíveis na maioria dos museus. A própria miniaturização dos circuitos internos de muitos instrumentos e equipamentos traz problemas de outra ordem, inclusive de compreensão de como se estruturam e articulam. 

químicos, em especial os reagentes antigos (reagentes de laboratório), e outros que também envolvem materiais com risco potencial para a saúde humana, como o mercúrio e os materiais radioativos. exemplo, enquanto os recipientes de vidro que contém esse metal estão íntegros, não há qualquer problema relacionado à contaminação ambiental. No entanto, no momento em que ocorrem trincas, rachaduras ou quebra do vidro, o mercúrio, que é líquido à temperatura ambiente, vazará e se dispersará na forma de micro-esferas, tornando a identificação da contaminação difícil pelos profissionais de museus e exigindo uma descontaminação de todo o local, incluindo solas de sapatos que levam a contaminação para outros locais. A partir daí, o mercúrio poderá passar para a fase vapor e se constituir em contaminante extremamente danoso à saúde. Importante é, portanto, condicionar esses instrumentos de forma a minimizar o risco de quebra e mesmo colocá-los em sacos de plástico especial, vedado, que não permita trocas com o ambiente.

Quanto aos reagentes químicos antigos, herança de muitos laboratórios químicos em universidades e mesmo de escolas secundárias, separar o conteúdo de seus recipientes e neutralizá-los constitui-se numa ação que descaracteriza e interfere profundamente no objeto científico antigo. Por outro lado, a sua permanência pode determinar riscos para outros objetos e, especialmente, para os profissionais da documentação, da pesquisa e da conservação que os manuseiem. $O$ mesmo se pode dizer em relação a objetos científicos mais recentes, onde a presença de radioatividade pode causar enormes danos, haja vista o acidente com césio-137 (radioativo) em Goiânia (Brasil) ${ }^{4}$.

É certo que a segurança das pessoas é aspecto primordial e que deve ser prioritária na conservação, assim, recomenda-se a neutralização dos reagentes e sua substituição nos frascos antigos por materiais inertes de mesma consistência e coloração para possibilitar a melhor comunicação do objeto com o público, seguindo a linha de abordagem de Salvador Muñoz Viñaz. O público deve ser informado sobre a substituição e sobre os riscos de manter o reagente original no ambiente museológico.

Outro aspecto, para além dessa diversificação de materiais, consiste na variação de modelos e na corrida frenética dos fabricantes pela atualização constante, com novos artefatos sendo produzidos com mais rapidez (telefones celulares são um ótimo exemplo). Aqui se percebe uma relação direta com o funcionamento dos objetos. Instrumentos científicos antigos, anteriores ao século $\mathrm{XX}$, possuem, em geral, a maioria de suas partes expostas à observação visual e possibilitam um entendimento mais fácil da forma como se articulam e como contribuem para o funcionamento do artefato. No entanto, à medida que nos defrontamos com instrumentos mais recentes percebe-se um distanciamento dessa forma de construir, migrando para as conhecidas "caixas pretas", onde todo o funcionamento está dentro de uma "caixa" a cujo conteúdo não se tem acesso, a menos que se desmonte o instrumento.

Na primeira etapa de conservação desse tipo de objetos ${ }^{5}$, ao abrir a "caixa preta" o conservador pode se deparar com sistemas muito complexos de peças e microchips que não são triviais para a percepção de sua função e articulação para o funcionamento do aparato. Sugere-se aqui privilegiar a conservação preventiva e atuar na documentação, pesquisa e guarda dos objetos em condições ambientais que favoreçam a sua permanência no tempo. 
59 Nesse contexto, o que devemos preservar para as futuras gerações? Claramente é impossível separar pelo menos um objeto científico que apresente inovação para fazer parte dos acervos de museus de C\&T e documentar esse ritmo frenético em que vivemos, especialmente no que tange a espaços de guarda, que são cada vez mais limitados. Aliado a isso, os desafios de conservação de objetos com tal variedade de materiais são aparentemente insuperáveis.

60 No Brasil, verifica-se que a maioria dos artefatos científicos mais antigos já se perdeu (Granato et al. 2010). Restam exemplares em alguns museus em condições de preservação diversas e, praticamente, nenhuma instituição museológica possui um programa de coleta ativa de peças para seus acervos de ciência e tecnologia que permita a sua atualização. Essa situação é dramática e constitui um grande desafio para a preservação do patrimônio cultural no país. Por estar consciente desse problema, o Museu de Astronomia e Ciências Afins (MAST) tem envidado esforços no sentido de multiplicar suas ações de cooperação e parceria com outras instituições, de forma a favorecer a preservação dos acervos in situ que guardam, e desenvolve várias iniciativas de pesquisa que pretendem ampliar o conhecimento sobre esse tipo específico de patrimônio, seja com relação aos valores simbólicos associados, seja com o desenvolvimento de metodologias de conservação e treinamento de pessoal. Espera-se que a continuidade dessas iniciativas promova a formação de agentes multiplicadores e um panorama mais positivo com relação à salvaguarda dos acervos de instrumentos científicos.

\section{6 - Considerações Finais}

61 embasamento teórico para a atividade de conservação de bens culturais é fundamental para seu melhor exercício prático. No entanto, nas últimas décadas, percebe-se pouca discussão e reflexão sobre o tema. Por outro lado, o investimento nas pesquisas e em pessoal, para o desenvolvimento de ensaios e análises que permitam conhecer mais os processos de degradação, os constituintes dos bens a serem conservados e o desenvolvimento de novos produtos para a conservação, é cada vez maior. A tal ponto, que muitas vezes parece que a atividade de conservação consiste apenas em processos objetivos de decisão e escolha. Todo processo de conservação inclui também decisões subjetivas, das quais o conservador não pode escapar, e sobre as quais tem responsabilidade.

No caso dos objetos científicos, a sua preservação relaciona-se com a memória científica e questões teóricas importantes também se colocam para esse tipo de acervo. Ainda são muitos os profissionais de museus de ciência, especialmente aqueles voltados para a área educativa, que acreditam na utilização de instrumentos científicos em funcionamento, como forma de aproximação com o público. Essa concepção inadequada é resultado do pouco debate teórico e filosófico que existe no país (Brasil) e muitas vezes, dentro de uma mesma instituição, concepções diferentes de preservação desses acervos podem coexistir, criando uma situação de tensão que pode resultar, em algum momento, na má utilização dos artefatos e no comprometimento de sua existência para as gerações futuras.

Por outro lado, esse tipo de objetos tem especificidades e são constituídos de diferentes materiais, o que torna muitas vezes complexa a execução de procedimentos de conservação. A ausência de profissionais capacitados também é um fator limitador. 0 
MAST possui um laboratório de Conservação de Objetos Metálicos (LAMET) onde técnicos especializados na abordagem de instrumentos científicos têm passado sua experiência para alunos de pós-graduação e profissionais interessados no tema. No entanto, é uma iniciativa que não tem como atender à demanda potencial. O contato com os diversos locais no Brasil que possuem conjuntos de objetos desse tipo permitiu verificar que em sua quase totalidade, não há capacitação para a conservação desse patrimônio.

A partir dos estudos realizados, verifica-se que os conjuntos em melhor situação de preservação no Brasil são aqueles que estão sob a guarda de museus ou instituições militares. Uma parte substancial de instituições e de artefatos de interesse para o projeto está no âmbito das universidades e a sua situação, em geral, é dramática.

o maior conhecimento desses conjuntos propicia a possibilidade de futuramente estruturar-se uma política de estado para a preservação desse tipo de patrimônio, incluindo critérios que possibilitem a escolha do que deve ou não ser preservado e, para além, quais são os desafios de conservação que estarão postos para serem superados.

\section{BIBLIOGRAFIA}

Boito, Camillo. 2002. Os Restauradores. Artes \& Ofícios. Cotia: Ateliê Editorial.

Brandi, Cesare. 2000. Teoria de la restauración. Madrid: Alianza Ed.

Brenni, Paolo. 1986. "Cleaning and relacquering of brass scientific instruments". Bulletin of the Scientifique Instrument Society (10):2-3.

Brenni, Paolo. 2000. Better than new? Scientific instrument restoration in Italy. In Restoration of Scientific Instruments: Proceedings of the workshop held in Florence, December 14-15, 1998, Instituto e Museo di Storia dela Scienza, 89-97. Florence: Le Lettere.

Choay, Françoise. 1996. A alegoria do patrimônio. São Paulo: Editora Unesp.

Cunha, Claudia dos Reis. 2006. "Alois Riegl e o 'Culto moderno dos monumentos”". Revista CPC 2:6-16. http://www.usp.br/cpc/v1/php/wf07_revista_interna.php?

id_revista=6\&id_conteudo=16\&tipo=5 (consultado em fevereiro 12, 2012).

Gilberg, Mark. 1987. "Friedrich Rathgen: the father of modern archaeological conservation". Journal of the American Institute for Conservation 26(2):105-120.

González-Varas, Ignacio. 2008. Conservación de Bienes Culturales. Teoria, historia, princípios y normas. Madrid: Ediciones Cátedra.

Granato, Marcus. 2007. “Apresentação”. Vol. 9 (MAST Colloquia) Conservação de Acervos, org. Marcus Granato et al., 5-14. Rio de Janeiro: MAST.

Granato, Marcus e Françoise Le Guet Tully. 2009. "Les principes de la restauration d instruments scientifiques: le cas du cercle méridien Gautier de l'observatoire de Rio de Janeiro". In Situ. Revue des patrimoines (10):1-34. 
Granato, Marcus, Elias da Silva Maia e Roberta Nobre da Camara. 2010. “Valorização do patrimônio científico e tecnológico brasileiro: concepção e resultados preliminares”. In Anais do XI Encontro Nacional de Pesquisa em Ciência da Informação. João Pessoa: ENANCIB, (1):1-16.

Granato, Marcus e Luiz Roberto Martins de Miranda. 2011. “A Restauração na Trajetória de um Teodolito do Acervo do MAST”. Anais do Museu Paulista (Impresso) (19):47-80.

Grattan, David. 1993. Proceedings of a Conference. Symposium '91 - Saving the Twentieth Century, Ottawa, Canada, 15 to 20 September, 1991. Ottawa: Canadian Conservation Institute.

Justicia, María José Martínez et al. 2008. La Restauración de Bienes Culturales en los Textos Normativos. Selecion, Traducion y Estudio Crítico de Documentos Normativos Internacionales y Nacionales. Granada: Editoral Comares.

Kühl, Beatriz Mugayar. 2006. "História e Ética na Conservação e na Restauração de Monumentos Históricos”. REVISTACPC 1(1).

http://www.usp.br/cpc/v1/php/wf07_revista_capa.php?id_revista=2 (consultado em fevereiro 12, 2012).

Macarrón, Ana. 2008. Conservación del Patrimonio Cultural. Criterios y Normativas. Madrid: Editoral Sintesis.

Maia, Elias da Silva e Marcus Granato. 2011. “A Conservação de Objetos de C\&T: Análise e discussão das práticas utilizadas no Memorial Carlos Chagas Filho”. Museologia e Patrimônio (3):1-14. http://revistamuseologiaepatrimonio.mast.br/index.php/ppgpmus/article/ view/96/129. (consultado em fevereiro 12, 2012).

Mann, Peter R. 1994. "Working exibits and the destruction of evidence in the Science Museum". In Care of Collections (Leicester Readers in Museum Studies Series), 35-50. London: Routledge.

Miniati, Mara e Brenni, Paolo. 1993. "Restauro di strumenti storico-scientifici e filosofie di intervento". In Restauro di Strumenti i Materialli: scienza, musica, etnografia, ed. M. Bitelli, 51-57. Florence: Nardini Editore.

Mohen, Jean-Pierre. 1999. Les sciences du patrimoine: identifier, conserver, restaurer, 181-232. Paris: Odile Jacob.

Muñoz Viñas, Salvador. 2005. Contemporary theory of conservation. Oxford e Burlington: Elsevier Butterworth-Heinemann.

Newey, Hazel. 2000. "Conservation and the preservation of scientific and industrial collections". In Proceedings of the International Congress of the International Institute for Conservation of Historic and Artistic Works (IIC), 18, 2000. Melbourne: Preprint.

Price, Nicholas Stanley, Mansfiled Kirby Talley Jr. e Alessandra Melucco Vaccaro. ed. 1996. Historical and philosophical issues in the conservation of cultural heritage. Los Angeles: The Getty Conservation Institute.

Riegel, Alois. 2006. O culto moderno dos monumentos: sua essência e sua gênese. Tradução Elaine R. Peixoto e Albertina Vicentine. Goiânia: Universidade Católica de Goiás.

Ruskin, John. 2008. A Lâmpada da Memória. Cotia: Ateliê Editorial.

Simpson, Mette Tang e Michael Huntley. 1996. La Restauration des Objets Anciens. Les Instruments Scientifiques, 95-101. Paris: Armand Colin Ed.

Shashoua, Yvonne. 2008. Conservation of Plastics: materials science, degradation and preservation. Oxford: Elsevier. 
Thomson, Garry. 1988. The Museum environment. 2..$^{\mathrm{a}}$ ed. London: Butterworth-Heinmann.

Viollet-le-Duc, Eugène Emmanuel. 2000. Restauração. Artes \& Ofícios. Cotia: Ateliê Editorial.

\section{NOTAS}

1. Termo complexo e que só se aplica em período histórico determinado (século XIX e início do século XX); refere-se a aparatos científicos e tecnológicos, incluindo aqui as montagens de laboratório. De forma mais geral, pode-se utilizar o termo "objetos de ciência e tecnologia" (Granato et al. 2007).

2. John Ruskin, Biographical Materials. The Victorian Web: literature, history, culture in the age of Victoria. National University of Singapore: http://www.victorianweb.org/authors/ruskin/ ruskinov.html (consultado em abril 5, 2012).

3. O Museu de Astronomia e Ciências Afins (MAST) vem realizando um levantamento nacional de conjuntos de objetos de valor científico e a percepção que se tem é que boa parte, especialmente os objetos mais antigos, já foi descartada. Sobre o projeto "Valorização do patrimônio científico e tecnológico brasileiro" pode consultar-se: http://www.mast.br/projetovalorizacao/index.html (consultado em abril 5, 2012). Os resultados iniciais já foram publicados (Granato et al. 2010).

4. A contaminação teve início em 13 de setembro de 1987, quando um aparelho utilizado em radioterapias das instalações de um hospital abandonado foi encontrado, na zona central de Goiânia. O instrumento foi encontrado por catadores de papel, que entenderam tratar-se de sucata. Foi desmontado e repassado para terceiros, gerando um rastro de contaminação que afetou seriamente a saúde de centenas de pessoas.

5. A conservação de instrumentos científicos apresenta as seguintes etapas gerais: higienização superficial, desmontagem, nova higienização mais detalhada e profunda e remontagem. As etapas constituintes do processo de restauro são: desmontagem das peças, conservação de algumas peças, restauração de boa parte das peças e substituição de algumas peças ausentes (Granato e Miranda 2011, 58).

\section{RESUMOS}

O patrimônio cultural material tem um tempo limitado de existência. Para prolongar a sua integridade física, a conservação tem como meta estabelecer estratégias de prevenção e de intervenção. Essas estratégias devem ser fortemente embasadas por uma fundamentação teórica. No presente trabalho foram analisados em caráter geral, os principais teóricos da conservação e as linhas predominantes em cada período, a partir do século XIX até a atualidade (Ruskin, Violetle-Duc, Boito, Brandi, Muñoz Viñaz, dentre outros). A seguir, foram discutidas brevemente as correntes de pensamento da conservação para instrumentos científicos, relacionando com o pensamento de alguns teóricos da conservação já apresentados. Finalmente, são enfocados os desafios na conservação de acervos científicos, dificuldades que são causadas seja pela quase ausência de profissionais qualificados na área, do número crescente de objetos adquiridos para as coleções ou da própria especificidade do acervo. Três aspectos principais foram discutidos: os materiais constituintes, o funcionamento do objeto científico e a questão da coleta de peças do patrimônio científico na atualidade. 
Material cultural heritage has a limited time of existence. One of the goals of conservation, designed to prolong the physical integrity of this heritage, involves devising prevention and intervention strategies. These strategies should be firmly rooted in theory. In this article, the theoretical principles of conservation are analyzed in broad terms, as are the prevailing approaches adopted at different times, from the 19th century to the present day (Ruskin, Violetle-Duc, Boito, Brandi, Muñoz Viñaz, and others). The article also focuses on the specific challenges of conserving scientific collections, which are caused by the virtual absence of qualified professionals in the area, the growing number of objects acquired for collections and the very nature of the collections themselves. Three main aspects were discussed: constituent materials of the scientific objects, the function of the instruments and the collection of pieces of scientific heritage today.

\section{ÍNDICE}

Keywords: cultural heritage, conservation theories, scientific collections, scientific instruments Palavras-chave: teorias da conservação, acervos científicos, património cultural, instrumentos científicos

\section{AUTORES}

\section{MARCUS GRANATO}

Formado em engenharia metalúrgica e de materiais pela UFRJ (1980), M.SC. (1993) e D.Sc. (2003) pelo Programa de Pós-Graduação da Escola de Engenharia Metalúrgica (COPPE/UFRJ), sendo sua tese sobre Restauração de Instrumentos Científicos Históricos. É Coordenador de Museologiano Museu de Astronomia e Ciências Afins - MAST e, a partir de 2006, torna-se professor do Programa de Pós-Graduação em Museologia e Patrimônio (UNIRIO/MAST), onde atua como vicecoordenador. As linhas principais de investigação relacionam-se aos estudos sobre o patrimônio científico e à conservação de objetos metálicos; é líder de grupo de pesquisa na área de Preservação de Bens Culturais do MAST. marcus@mast.br

\section{GUADALUPE DO NASCIMENTO CAMPOS}

Possui Graduação em Museologia pela Universidade do Rio de Janeiro (1996), M.Sc (2001) e D.Sc. (2005) em Ciência dos Materiais e Engenharia Metalúrgica pela Pontifícia Universidade Católica do Rio de Janeiro. Consultora em Arqueologia Histórica para a Fundação Roberto Marinho e o Banco Central. Atualmente desenvolve pesquisas a nível de pós-doutorado no Museu de Astronomia e Ciências Afins - MAST sobre a conservação de artefatos arqueológicos metálicos. guadalupecampos@mast.br 